\title{
Evaluation of apertura piriformis and related cranial anatomical structures through computed tomography: golden ratio
}

\author{
S. Sertel Meyvaci ${ }^{1}$, R. Kosif ${ }^{1}$, B. Bamaç², M. Hizal ${ }^{3}$, H. Ankarali4 \\ ${ }^{1}$ Department of Anatomy, Faculty of Medicine, Bolu Abant Izzet Baysal University, Bolu, Turkey \\ 2Department of Anatomy, Faculty of Medicine, Kocaeli University, Kocaeli, Turkey \\ ${ }^{3}$ Department of Radiology, Faculty of Medicine, Bolu Abant Izzet Baysal University, Bolu, Turkey \\ ${ }^{4}$ Department of Biostatistics and Medical Informatics, Faculty of Medicine, Istanbul Medeniyet University, Istanbul, Turkey
}

[Received: 24 December 2018; Accepted: 7 February 2019]

Background: The purpose of study was to evaluate normal morphometric measurements of piriform aperture (PA) by limiting the age range in genders to show the morphometry of the relevant and close proximal cranial structures; and also to investigate whether these are in compliance with the golden ratio.

Materials and methods: Our study was performed on 83 (42 female, 41 male) multidetector computed tomography images obtained from patients. A total of 14 morphological measurements were performed including the height of PA, the width of PA and 12 cranial structures; and these measurements were evaluated for compliance with the golden ratio. The differences of 14 parameters between the genders and age groups, and also the interaction of these two factors were analysed.

Results: In our morphometric study, significant difference between the genders was found in all measurements except for the distance between vertex and rhinion $(V \sim R h)$, between rhinion and right foramen supraorbitalis $\left(R h \sim F S O_{R}\right)$, between rhinion and left FSO (Rh FSOL), and the width of PA on the level between the right and left foramen infraorbitalis (PAW FIO) with the difference valid for both age subgroups ( $p<0.05$ ). When the differences between the age subgroups were evaluated, there was significant difference only at the widest distance of cranium (CW; $p=0.008$ ); and it was observed that the average has increased with age in both genders. When the golden ratio was examined, the ratio of the distance between anterior nasal spine and nasion to the height of piriform aperture (NSA N:PAH) was found to be within the limits of the golden ratio in males $(p=0.074)$. No golden ratio has been found in females.

Conclusions: In our study, significant differences were detected between genders in all parameters of PA and in some parameters of the close cranial structures in the age group we examined. The effect of age was detected only in the CW parameter, and the PA and close cranial structures were not affected. In our study, the averages of the morphometric measurements of 13 parameters of young adults were determined. The PA and surrounding cranial structures are important for the area and related surgical procedures; however, gender differences must be considered in this respect. In addition to this, in the PA, which is the anterior limit of the skeletal nose in males, the NSA N:PAH ratio having the ideal golden ratio limits is valuable in aesthetical terms and due to its position of the PA in the face. (Folia Morphol 2019; 78, 4: 839-846)

Key words: piriform aperture, cranial parameters, morphometry, computed tomography, golden ratio 


\section{INTRODUCTION}

The piriform aperture (PA) is the essential localisation in the centre of the skeletal craniofacial area. PA is bordered by the nasal bones, the frontal processes of the maxillary bones and the anterior nasal spine [17]. This skeletal aperture is the anterior limit of the skeletal nose and includes the main factors to create the actual shape, size and form of the nose $[13,20]$. The number of studies on PA is limited. Data on morphology vary according to ethnic differences, sexual dimorphism and age-related changes of the PA, which have already been published $[4,6,11]$. Studies have focused on the relationship between the nasal bone and PA, the shape of the PA and the size of the PA $[7,12,19]$. PA is affected by changes in age, ethnicity and sexual dimorphism $[1,8,14]$. Facial skeleton changes with age. The most significant amount of bony change occurs within the mid-cheek skeleton. This leads to a reduction of the bony rim of the PA [8]. For this reason, age should also be taken into account for the interpretation of data pertaining to the morphometry of the PA. Studies in the literature kept the age range wide without exhibiting the changes caused by age. Since there would be age-related changes in the face, the mean measurements need to be grouped according to age. In our study, we kept the age range narrow and limited it with 21 to 30 years.

Although previous studies were conducted by considering the gender, age and ethnicity, the number of such studies is limited and the cranial parameters associated with the PA are insufficient. In order to obtain relevant data, methods such as direct measurements over the skull, radiography and computed tomography $(\mathrm{CT})$ were used $[3,9,16]$. Three-dimensional (3D) CT of piriform aperture is an efficient technique for acquiring quantitative and objective data [10]. However, when we examined the literature with regard to the morphology of the $\mathrm{PA}$, we determined that clear data related to age limitations had not been provided for males and females. Additionally, there are no studies examining whether PA-related measurements comply with the golden ratio.

The aim of this study is to evaluate the normal morphometric measurements of the PA with the aid of $\mathrm{CT}$ by limiting the age range in both genders; to exhibit the morphometry of the related and near proximal cranial structures, and to examine whether these comply with the golden ratio.

\section{MATERIALS AND METHODS}

This study was approved by the Bolu Abant Izzet Baysal University, Clinical Researches Ethics Committee, with Decision No: 2017/169. Head CT images of the patients who have been admitted to the hospital and requested head CT examination by either emergency department or neurology department with minor head trauma, suspicion of intracranial haemorrhage between November 2017 and April 2018 have been evaluated retrospectively. There were 41 male and 42 female patients in the sampling. Since the most significant amount of bony change occurs in the mid-cheek skeleton leading to a reduction of the bony rim of the $\mathrm{PA}$, the age range was limited to 21-30 in our study. In our study, we limited the age range as $21-30$ to achieve the morphometric normative data of the parameters of the young adults; and wanted to strengthen our study by separating the cases into two subgroups as $21-25$ and $26-30$.

Nasal pyramid and related cranial anatomical structures of 83 patients were analysed with 3D CT. These patients had no diseases affecting the structure of the cranium, did not have maxillofacial congenital structural anomalies and did not have intracranial haemorrhage and surgery or any specific findings on the CT scan.

\section{CT protocol}

All patients underwent $C T$ using a 64-slice multi-detector CT (MDCT) device (Revolution EVO, GE healthcare, Waukesha, WI, the USA) with the same examination protocol using $64 \times 0.5 \mathrm{~mm}$ collimation scanner with a gantry rotation speed of $400 \mathrm{~ms} /$ rotation, range of box 450-500, image thickness $5 \mathrm{~mm}$, standard pitch factor of 0.641 , reconstruction interval $0.625 \mathrm{~mm}$ and a total exposure time 11 seconds. Each scan was obtained with a tube voltage of $120 \mathrm{KV}$ and $320 \mathrm{mAs}$. Images were transferred to a separate workstation (GE, Advantage Workstation 4.4) for measurements.

\section{Measurements}

All patients underwent $\mathrm{CT}$ examination in supine position. Axial reconstructed images with $0.625 \mathrm{~mm}$ thickness were obtained from the $\mathrm{CT}$ images on the axial plane, then 3D volume rendered (VR) images were obtained from these thin slice reconstructed images. In order to make the measurements, in all patients, centre of the nasion was brought to the centre of the transverse plane, and the image with 


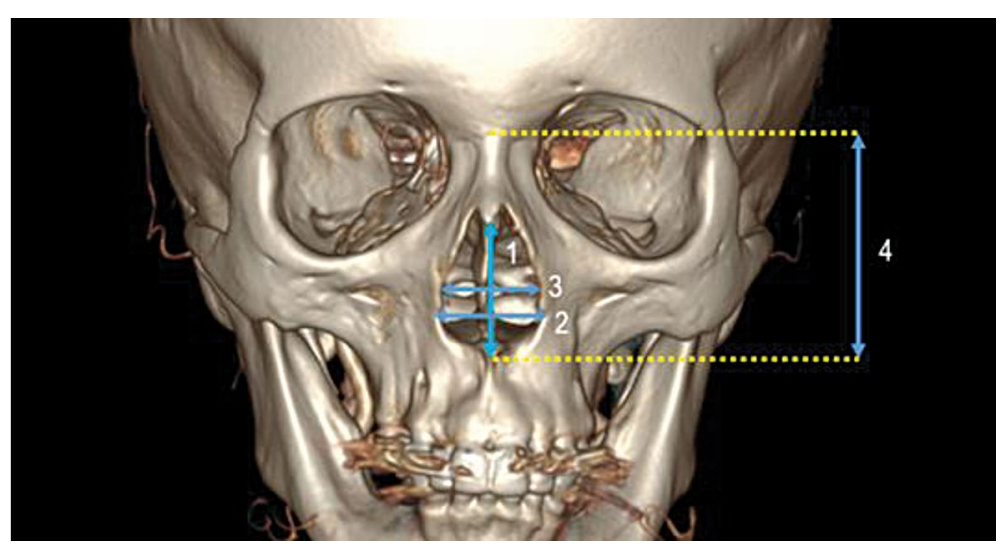

Figure 1. Illustration of four parameters related to piriform aperture measurements on three-dimensional reconstruction of computed tomography scan: 1 - $\mathrm{PAH} ; 2$ - PAW; 3 - PAW FI0; 4 - NSA N ; abbreviations - see text.

the maximum distance between the vertex and the prosthion was used. All reconstructions, VR image adjustments and measurements were made manually by a single neuroradiologist with 5 years of experience.

A total of 14 measurements including apertura piriformis and related anatomical parameters were performed on 3D-reconstructions of facial CT images. The parameters were measured in millimetres $(\mathrm{mm})$ and there was one-step measurement accuracy after the point. In addition, for each patient, the age, height, weight, gender, and 14 measurements were recorded in Excel.

\section{Measurements and abbreviations of measured 14 parameters}

- The height of PA (PAH) - maximal height of PA was measured from the rhinion to the anterior nasal spine;

- The width of PA (PAW) - maximal width of PA was measured as the widest between the left and right bone margin on transverse plane;

- The width of PA on the level between of the right and left foramen infraorbitalis $(\mathrm{PAW} \sim \mathrm{FIO})-$ the distance between the right and left sides of the PA was measured in the transverse plane that passed the foramen infraorbitalis level;

- The distance between anterior nasal spine and nasion $(N S A \sim N)-N S A \sim N$ was measured as the maximal distance between anterior nasal spine and nasion (Fig. 1);

- The distance between anterior nasal spine and prosthion (NSA Pr) - NSA Pr was measured as the maximal distance between anterior nasal spine and prosthion;
- The widest distance of cranium $(\mathrm{CW})$ - CW was measured as the widest point between right and left side of cranium on transverse plane;

- The widest distance of cranium on the level of PA $(C W \sim P A)-C W \sim P A$ was measured as the widest point between right and left side of cranium on transverse plane of equivalent of PA;

- The distance between right and left $\mathrm{FIO}\left(\mathrm{FIO}_{\mathrm{R}} \sim \mathrm{FIO}_{\mathrm{L}}\right)$ - $\mathrm{FIO}_{\mathrm{R}} \sim \mathrm{FIO}_{\mathrm{L}}$ was measured as the distance between the midpoint of right $\mathrm{FIO}$ and left $\mathrm{FIO}$ on transverse plane;

- The distance between vertex and rhinion $(\mathrm{V} \sim \mathrm{Rh})$ $-\mathrm{V} \sim \mathrm{Rh}$ was measured as the maximal distance between vertex and rhinion (Fig. 2);

- The distance between vertex and prosthion ( $\mathrm{V} \sim \mathrm{Pr})$ - $\mathrm{V} \sim \operatorname{Pr}$ was measured as the maximal distance between vertex and prosthion;

- The distance between rhinion and right foramen supraorbitalis $\left(\mathrm{Rh} \sim \mathrm{FSO}_{\mathrm{R}}\right)-\mathrm{Rh} \sim \mathrm{FSO}_{\mathrm{R}}$ was measured as the distance between rhinion and the midpoint of right foramen supraorbitalis (FSO);

- The distance between rhinion and left FSO $\left(\mathrm{Rh} \sim \mathrm{FSO}_{\mathrm{L}}\right)-\mathrm{Rh} \sim \mathrm{FSO}_{\mathrm{L}}$ was measured as the distance between rhinion and the midpoint of left FSO;

- The distance between rhinion and right $\mathrm{FIO}\left(\mathrm{Rh} \sim \mathrm{FIO}_{\mathrm{R}}\right)$ - $\mathrm{Rh} \sim \mathrm{FIO}_{\mathrm{R}}$ was measured as the distance between rhinion and the midpoint of right FIO;

- The distance between rhinion and left $\mathrm{FIO}\left(\mathrm{Rh} \sim \mathrm{FIO}_{\mathrm{L}}\right)$ - $\mathrm{Rh} \sim \mathrm{FIO}_{\mathrm{L}}$ was measured as the distance between rhinion and the midpoint of left FIO (Fig. 3); In addition, for each patient, the ratio of the distance between anterior nasal spine and nasion to the height of piriform aperture (NSA N:PAH) and the ratio of the height of PA to the width of PA (PAH:PAW) were measured to evaluate the golden ratio. 


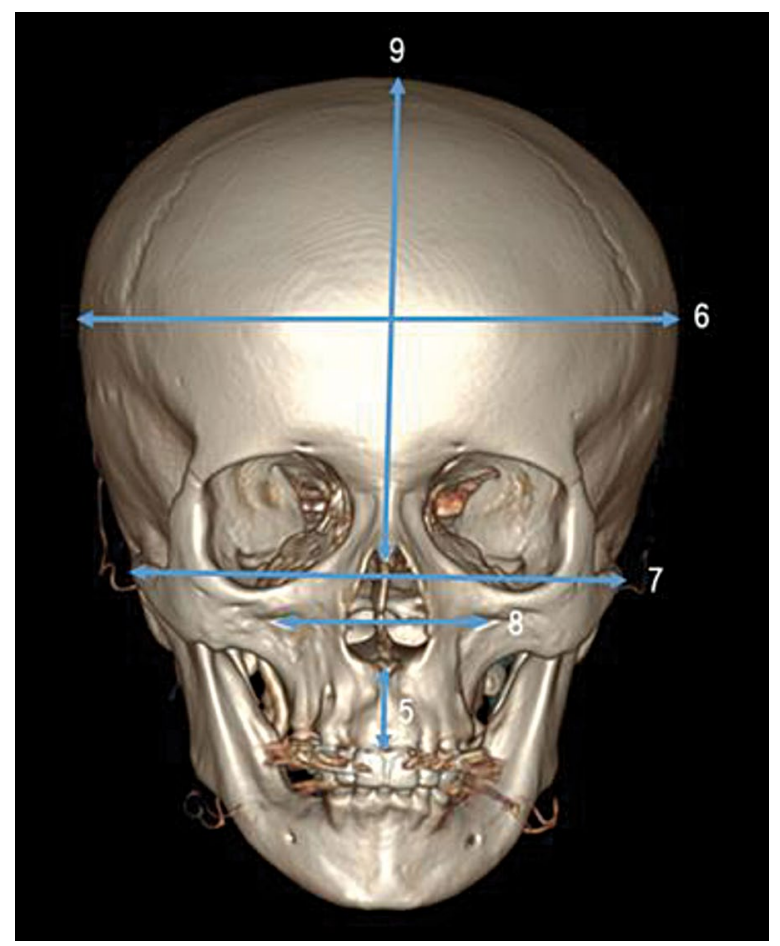

Figure 2. Illusttration of five parameters related to cranial anatomical structures on three-dimensional reconstruction of computed tomography scan; $5-\mathrm{NSA} \sim \mathrm{Pr} ; 6-\mathrm{CW} ; 7-\mathrm{CW} \sim \mathrm{PA}$; $8-\mathrm{FIO}_{\mathrm{R}} \sim \mathrm{FIO}_{\mathrm{L}} ; 9-\mathrm{V} \sim \mathrm{Rh}$; abbreviations - see text.

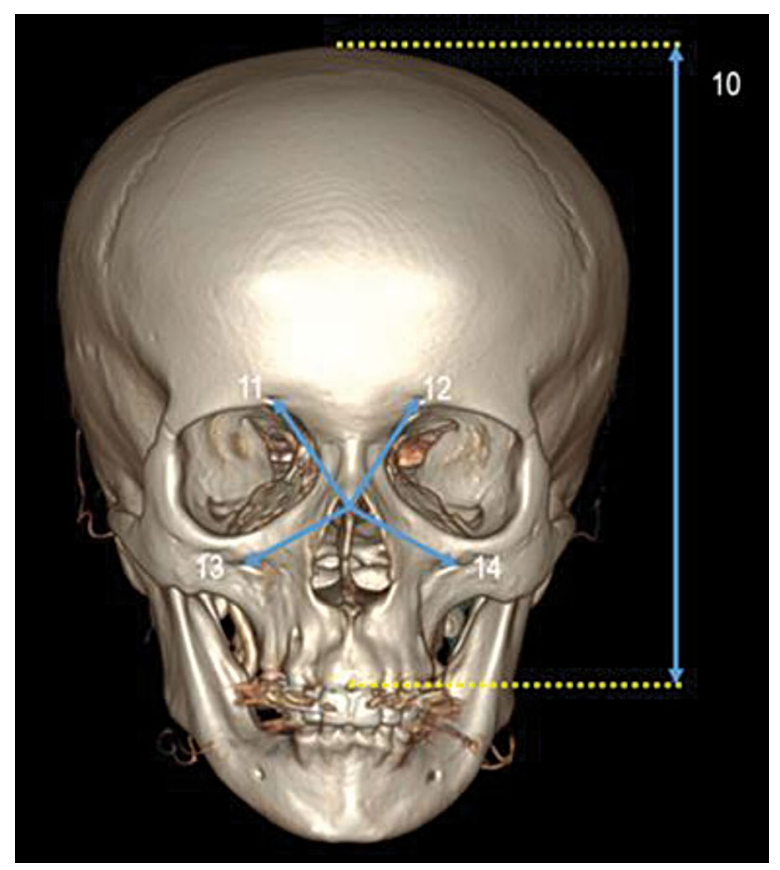

Figure 3. Illusttration of five parameters related to cranial anatomical structures on three-dimensional reconstruction of computed tomography scan; $10-\mathrm{V} \sim \mathrm{Pr} ; 11-\mathrm{Rh} \sim \mathrm{FSO}_{\mathrm{R}} ; 12-\mathrm{Rh} \sim \mathrm{FSO}_{\mathrm{L}^{\prime}}$; $13-\mathrm{Rh} \sim \mathrm{FIO}_{\mathrm{R}} ; 14-\mathrm{Rh} \sim \mathrm{FIO}_{\mathrm{L}}$; abbreviations - see text.

\section{Statistical analysis}

The descriptive values of the data were calculated as mean \pm standard deviation (SD). The differences between the genders and the age groups, and also the interaction of these two factors were analysed by factorial analysis of variance with two factors. The correlation between the parameters was analysed using Pearson correlation test. One sample t-test was used to compare the golden ratio. $\mathrm{P}<0.05$ was considered statistically significant in the statistical test results; and the SPSS (ver. 18) programme was used for analyses.

\section{RESULTS}

In the current study, descriptive values of demographic data of each gender are given in Table 1 . A positive significant correlation was found between height and $\mathrm{Rh} \sim \mathrm{FSO}_{\mathrm{R}}(r=0.379, \mathrm{p}=0.013), \mathrm{Rh} \sim \mathrm{FSO}_{\mathrm{L}}$ $(r=0.374, p=0.015)$ and $N S A \sim N(r=0.321$, $p=0.038$ ) in males. However, there were no significant relations between any parameters and body mass index (BMI) or weight. In females, on the other hand, a positive significant correlation was found between height and PAW ( $r=0.457, p=0.003)$, height and NSA N $(r=0.332, p=0.034)$, and also weight and PAW ( $r=0.351, p=0.025)$. However, no significant relationship could be found between any parameter and BMI in females.

According to analysis, the interaction between age groups and gender was not significant for each variable in Table 2. Also, the mean values of males were significantly higher than that of females for all variables ( $p<0.01$ ), except $V \sim R h, R h \sim F S O R$, $\mathrm{Rh} \sim \mathrm{FSOL}$, and $\mathrm{PAW} \sim \mathrm{FIO}$ variables. When the differences between the genders are examined according to changes at the age subgroups, the differences was seen to be acceptable in both age subgroups.

In addition, when the difference between the two age groups were examined, it was seen that there was only a significant difference in CW ( $p<0.01)$, and this result was not change according to gender.

In addition, the 14 variables in Table 2 were compared to examine whether they complied with the golden ratio. Only NSA N:PAH and PAH:PAW were found to be close to the golden ratio (approximately equal to 1.618). But, there were found statistically significant difference between the golden ratio and mean ratio of the NSA N:PAH ( $p=0.001)$, which was high and not complying with the golden ratio. The mean PAH:PAW was also found to be lower 
Table 1. Demographic characteristics of all cases

\begin{tabular}{|c|c|c|c|c|c|c|}
\hline & \multicolumn{3}{|c|}{ Female } & \multicolumn{3}{|c|}{ Male } \\
\hline & $\mathbf{N}$ & Mean & SD & $\mathbf{N}$ & Mean & SD \\
\hline Height $[\mathrm{m}]$ & 42 & 1.63 & 0.06 & 41 & 1.75 & 0.07 \\
\hline Weight [kg] & 42 & 61.07 & 11.83 & 41 & 76.65 & 12.35 \\
\hline Age [years] & 42 & 23.95 & 3.43 & 41 & 25.41 & 4.13 \\
\hline BMI $\left[\mathrm{kg} / \mathrm{m}^{2}\right]$ & 42 & 22.99 & 4.59 & 41 & 24.96 & 3.55 \\
\hline
\end{tabular}

$\mathrm{BMI}$ - body mass index; SD — standard deviation

Table 2. The results of the comparisons between age groups and sexes with regard to the measurements performed

\begin{tabular}{|c|c|c|c|c|c|c|c|c|c|c|c|}
\hline \multicolumn{2}{|c|}{ Parameters } & \multirow{2}{*}{$\begin{array}{c}\text { Age groups } \\
21-25\end{array}$} & \multicolumn{3}{|c|}{ Female } & \multicolumn{3}{|c|}{ Male } & \multirow{3}{*}{$\begin{array}{c}\mathbf{P}_{\text {Sex }} \\
0.0001\end{array}$} & \multirow{3}{*}{$\begin{array}{c}\mathbf{P}_{\text {Age groups }} \\
0.701\end{array}$} & \multirow{3}{*}{$\begin{array}{c}\mathbf{P}_{\text {Sex } \times \text { Age groups }} \\
0.743\end{array}$} \\
\hline 1 & PAH & & $\begin{array}{l}\mathbf{N} \\
30\end{array}$ & $\begin{array}{c}\text { Mean } \\
29.15\end{array}$ & $\begin{array}{c}\text { SD } \\
2.77\end{array}$ & $\begin{array}{l}\mathbf{N} \\
20\end{array}$ & $\begin{array}{c}\text { Mean } \\
32.71\end{array}$ & $\begin{array}{c}\text { SD } \\
3.44\end{array}$ & & & \\
\hline & & $26-30$ & 12 & 29.62 & 2.86 & 21 & 32.74 & 2.37 & & & \\
\hline \multirow[t]{2}{*}{2} & PAW & $21-25$ & 30 & 22.23 & 2.31 & 20 & 23.35 & 1.75 & 0.005 & 0.704 & 0.612 \\
\hline & & $26-30$ & 12 & 21.81 & 1.32 & 21 & 23.40 & 2.10 & & & \\
\hline \multirow[t]{2}{*}{3} & PAW FIO & $21-25$ & 30 & 20.14 & 2.44 & 20 & 19.98 & 1.64 & 0.480 & 0.857 & 0.290 \\
\hline & & $26-30$ & 12 & 19.73 & 1.24 & 21 & 20.56 & 1.99 & & & \\
\hline \multirow[t]{2}{*}{4} & $\mathrm{NSA} \sim \mathrm{N}$ & $21-25$ & 30 & 49.83 & 2.32 & 20 & 53.72 & 2.74 & 0.0001 & 0.223 & 0.0958 \\
\hline & & $26-30$ & 12 & 50.70 & 3.55 & 21 & 54.51 & 3.49 & & & \\
\hline \multirow[t]{2}{*}{5} & $\mathrm{NSA} \sim \mathrm{Pr}$ & $21-25$ & 30 & 17.36 & 2.34 & 20 & 18.69 & 2.01 & 0.0001 & 0.229 & 0.223 \\
\hline & & $26-30$ & 12 & 17.35 & 1.86 & 21 & 19.97 & 2.54 & & & \\
\hline \multirow[t]{2}{*}{6} & CW & $21-25$ & 30 & 142.70 & 6.34 & 20 & 146.93 & 5.02 & 0.001 & 0.008 & 0.526 \\
\hline & & $26-30$ & 12 & 146.04 & 10.72 & 21 & 152.30 & 6.41 & & & \\
\hline \multirow[t]{2}{*}{7} & $C W \sim P A$ & $21-25$ & 30 & 128.02 & 3.84 & 20 & 136.89 & 4.42 & 0.0001 & 0.415 & 0.699 \\
\hline & & $26-30$ & 12 & 128.52 & 4.54 & 21 & 138.29 & 6.90 & & & \\
\hline \multirow[t]{2}{*}{8} & $\mathrm{FIO}_{\mathrm{R}} \sim \mathrm{FIO}_{\mathrm{L}}$ & $21-25$ & 30 & 46.56 & 3.96 & 20 & 49.35 & 4.17 & 0.0001 & 0.196 & 0.117 \\
\hline & & $26-30$ & 12 & 46.30 & 1.83 & 21 & 52.02 & 4.70 & & & \\
\hline \multirow[t]{2}{*}{9} & $\mathrm{~V} \sim \mathrm{Rh}$ & $21-25$ & 30 & 111.67 & 19.99 & 20 & 116.20 & 7.49 & 0.430 & 0.684 & 0.489 \\
\hline & & $26-30$ & 12 & 115.03 & 6.62 & 21 & 115.32 & 5.08 & & & \\
\hline \multirow[t]{2}{*}{10} & $\mathrm{~V} \sim \mathrm{Pr}$ & $21-25$ & 30 & 161.30 & 5.78 & 20 & 167.26 & 6.75 & 0.0001 & 0.833 & 0.770 \\
\hline & & $26-30$ & 12 & 162.01 & 5.41 & 21 & 167.14 & 6.35 & & & \\
\hline \multirow[t]{2}{*}{11} & $\mathrm{Rh} \sim \mathrm{FSO}_{\mathrm{R}}$ & $21-25$ & 30 & 38.60 & 4.04 & 20 & 37.98 & 4.30 & 0.666 & 0.257 & 0.841 \\
\hline & & $26-30$ & 12 & 39.51 & 4.58 & 21 & 39.29 & 4.16 & & & \\
\hline \multirow[t]{2}{*}{12} & $\mathrm{Rh} \sim \mathrm{FSO}_{\mathrm{L}}$ & $21-25$ & 30 & 37.65 & 3.06 & 20 & 36.54 & 5.75 & 0.715 & 0.100 & 0.493 \\
\hline & & $26-30$ & 12 & 38.68 & 5.67 & 21 & 39.02 & 4.37 & & & \\
\hline \multirow[t]{2}{*}{13} & $\mathrm{Rh} \sim \mathrm{FIO}_{\mathrm{R}}$ & $21-25$ & 30 & 27.88 & 3.64 & 20 & 30.50 & 2.85 & 0.0001 & 0.943 & 0.580 \\
\hline & & $26-30$ & 12 & 27.43 & 2.00 & 21 & 30.85 & 2.95 & & & \\
\hline \multirow[t]{2}{*}{14} & $\mathrm{Rh} \sim \mathrm{FIO}_{\mathrm{L}}$ & $21-25$ & 30 & 27.83 & 3.11 & 20 & 29.31 & 2.41 & 0.002 & 0.311 & 0.297 \\
\hline & & $26-30$ & 12 & 27.80 & 2.53 & 21 & 30.76 & 3.63 & & & \\
\hline
\end{tabular}

SD — standard deviation; other abbreviations — see text

at a significant level than the mean golden ratio $(p=0.001)$. This parameter did not comply with the golden ratio, either.
However, when males and females were examined separately, a significant difference between the mean NSA N:PAH and the golden ratio was 
Table 3. The mean values of the parameters related to the golden ratio

\begin{tabular}{lccccc}
\hline Sex & Golden ratio parameters & N & Mean & Standard deviation & P \\
\hline Male & NSA N :PAH & 41 & 1.6658 & 0.16671 & 0.074 \\
\multirow{3}{*}{ Female } & PAH:PAW & 41 & 1.4088 & 0.16780 & 0.001 \\
& NSA N $:$ PAH & 42 & 1.7244 & 0.17845 & 0.001 \\
All cases & PAH:PAW & 42 & 1.3352 & 0.17224 & 0.001 \\
& NSA N $:$ PAH & 83 & 1.6955 & 0.17421 & 0.001 \\
& PAH:PAW & 83 & 1.3716 & 0.17303 & 0.001 \\
\hline
\end{tabular}

Abbreviations - see text

not found only in males ( $p=0.074)$, which mean that the NSA $\sim \mathrm{N}: \mathrm{PAH}$ ratio was within the golden ratio limits in males. The $\mathrm{PAH}$ :PAW ratio in males, however, was found not to comply with the golden ratio. In females, both the NSA N $\mathrm{PAH}$ and $\mathrm{PAH}: \mathrm{PAW}$ ratios were found not to comply with the golden ratio (Table 3 ).

As a result, NSA $\sim \mathrm{N}: \mathrm{PAH}$ ratio was found to be consistent with golden ratio in males and no ratios were found to be compatible with golden ratio in females.

\section{DISCUSSION}

The PA has an important position since it is at the centre of the bone structure of the face, it forms the bone structure of the nasal entrance and it is the initial part of the respiratory tract $[5,13,15]$. Obtaining morphometric data about the PA and related cranial structures with regard to age, height, gender, and ethnicity is required for anthropology, forensic science, and surgical procedures. New morphometric data obtained by considering the demographic characteristics of the individual, especially ethnic differences, should be added to the literature with the studies which investigate the effects of these differences $[2,21]$. The morphometric evaluation of 3D CT technique is useful for obtaining reliable and objective data in anatomical studies [10,18]. Yuzbaşıoglu et al. [20] measured the PA length and width, and determined the PA length, PA width ratio; and evaluated the PA types of 120 subjects (58.23 \pm 16.24 age/ /years) by using 3D CT images. In this study, there was a significant difference between gender groups in terms of PA length and width. PA length was $33.4 \pm 2.9 \mathrm{~mm} ; 3.01 \pm 0.30 \mathrm{~mm}$ and width was $24.6 \pm 2.1 \mathrm{~mm} ; 23.3 \pm 0.1 \mathrm{~mm}$, thus the PA length:PA width ratio was determined as $13.6 \pm 1.7 ; 13.0 \pm 1.7$ in males and females, respectively. The PAs were classified into seven categories according to their shapes; however, the golden ratio was not evaluated.
Yuzbaşıoglu et al. [20] determined the PA length:PA width ratio was $1.36 \pm 0.17 \mathrm{~cm}$ in males, and $1.30 \pm$ $\pm 0.17 \mathrm{~cm}$ in females. Yuzbaşıoglu et al. [20] conducted a study and determined the age range as very wide. Although they did not divide the groups further to age subgroups, the rate of PA height to PA width and the averages of PA height and width were found to be similar with our study.

Karadag et al. [9] measured the PA width of 80 patients (age range 16-72) by using CT and found the PA width as $18.83 \pm 2.17 \mathrm{~mm}$ and $18.19 \pm 1.85 \mathrm{~mm}$ in men and women, respectively. There was no significant difference $(p=0.18)$ between gender groups in terms of PA width. When these results were compared with ours, it was seen that the PA width value was lower than that of ours. We believe that the reason for this might be the fact that the authors of the previous studies kept the age range very wide and included non-adult population in their studies.

Abdelaleem et al. [1] conducted a study on gender determination from the PA length, PA width and $\mathrm{PA}$ area in the Egyptian population (age range 19-78 years) by using 3D CT. PA length was found to be $38.24 \pm 7.82 \mathrm{~mm}, 35.12 \pm 6.05 \mathrm{~mm}$, PA width $30.53 \pm 6.68 \mathrm{~mm}$ and $27.08 \pm 2.88 \mathrm{~mm}$, in males and females, respectively. In this study, measurements revealed that males presented with significantly greater mean values than females. When the results were compared, it was determined that our measurement value was lower. This might be explained with the wider age range and different ethnicity. However, the golden ratio was not evaluated. Citardi et al. [5] developed a computer paradigm for the assessment of bony nasal pyramid dimensions by using CT scans; and reviewed the data obtained from 8 patients (mean age $37.5 \pm 20.4$ years). Nasal projection from the nasomaxillary suture to rhinion in the axial plane was $19.20 \pm 3.10 \mathrm{~mm}$ and the nasion nasal projection was $20.61 \pm 3.52 \mathrm{~mm}$. The averages between sides were 
statistically significant [5]. Naser et al. [10] studied 74 cone-beam CT images obtained from the Iranian population, and measured the PA width. There was no significant difference between males $(25.67 \pm 1.79 \mathrm{~mm})$ and females $(23.77 \pm 2.8 \mathrm{~mm})$ [10].

Prado et al. [16] evaluated radiographs of 97 individuals (age range 18-36 years) taken by Caldwell radiographic technique with front-nasal support [16]. In this study, the highest width of the PA, the height of the PA and area of PA were measured. Mean PA width was $35 \mathrm{~mm}$ in males, and $30 \mathrm{~mm}$ in females.

Hommerich et al. [6] measured the upper and lower PA width by using 3D CT in participants with an average age of 47 years. The mean lower PA width was $23.6 \pm 0.5 \mathrm{~mm}$ in men, and $22.6 \pm 0.5 \mathrm{~mm}$ in women. The mean upper PA width was $16.0 \pm 0.3 \mathrm{~mm}$ in men and $15.4 \pm 0.3 \mathrm{~mm}$ in women. In our study, we limited the age range and included individuals who between the ages of 21 and 30. Other studies have kept the age range very wide $[1,9,20]$.

In a study by Hommerich et al. [6], the cases were separated into groups of 10 according to age; and it was determined that the mean data varied with age. When the lower width of the piriform aperture was examined according to age groups, the greatest standard deviation in the 10-19 age group below the mean value $(20.6 \mathrm{~mm})$ was determined to be $2.5 \mathrm{~mm}$, and the mean value of the 40-49 age group, where the largest standard deviation was found, was $23.8 \mathrm{~mm}$ [6]. In our study, when we examined the cases in the 21-30 age range by separating them into 21-25 and 26-30 age subgroups, no difference between PAW values according to age groups was found in both genders.

In our study, the correlations of the parameters with height, weight, and BMI were evaluated. No correlations were detected with these variables in other studies.

In the present study, the mean PA height was $32.72 \pm 2.90 \mathrm{~mm}$ in males, and $29.28 \pm 2.77 \mathrm{~mm}$ in females. The mean PA width was $23.38 \pm 1.92 \mathrm{~mm}$ in males, and $22.11 \pm 2.07 \mathrm{~mm}$ in females. In the current study, the dimensions of the PA except for PAW $\sim \mathrm{FIO}$ were higher in males compared to females. Other parameters related to cranial anatomical structures except for $\mathrm{Rh} \sim \mathrm{FSO}_{\mathrm{R}^{\prime}}, \mathrm{Rh} \sim \mathrm{FSO}_{\mathrm{L}}$ and $\mathrm{V} \sim \mathrm{Rh}$ were higher in males compared to females.

As a second result of our study, we determined the golden ratio between the NSA N:PAH parameters. The mean NSA N:PAH value was found to be $1.66 \pm$ \pm 0.16 in males, and $1.72 \pm 0.17$ in females. Accord- ing to our results, only men's NSA N:PAH ratio was in compliance with the golden ratio.

\section{CONCLUSIONS}

Knowing the differences between genders is very important in fields such as forensic medicine, anthropology, and archaeology with regard to determining human identity $[2,11]$. In our study, the difference between genders was found to be valid in both the 21-25 and 26-30 age groups. These parameters included PAH, PAW, NSA N NSA Pr, CW, CW PA, $\mathrm{FIO}_{\mathrm{R}} \sim \mathrm{FIO}_{\mathrm{L}^{\prime}} \mathrm{V} \sim \mathrm{Pr}, \mathrm{Rh} \sim \mathrm{FIO}_{\mathrm{R}^{\prime}} \mathrm{Rh} \sim \mathrm{FIO}_{\mathrm{L}}$. In other words, all parameters of the $P A$ and some parameters of the close cranial structures were found to be significantly different between the genders.

Additionally, in our study in which we wanted to determine the morphometric normative data of young adults and limited the age range to $21-30$, when we considered the difference between age subgroups, we determined that there were no differences in any of the parameters in any gender except for the CW. The age range was not limited and was kept very wide in other studies and the difference between age groups was not considered. The difference in the CW parameter suggested that age should be taken into account when studies on CW parameters are performed. Through this study, the morphometric normative data of the other 13 parameters have been obtained for young adults and have been added to the literature.

Among the parameters related to PA, only the NSA N NAAH ratio was found to be within the limits of the golden ratio in males. When we examined studies in the literature similar to ours, we found no studies of the golden ratio and NSA N:PAH. This ratio was first detected in our study.

Although we limited the sexual dimorphism criteria and the age range with 21-30 in the cranial structures and in PA in the age group we included in our study, the results revealed especially the golden ratio and the $\mathrm{CW}$ parameter, which was affected by age. We believe that these anatomical data will be beneficial in maxillofacial procedures by plastic and reconstructive surgeons, for all pre-operative evaluation of surgical procedures, forensic anthropology and otolaryngology fields.

\section{REFERENCES}

1. Abdelaleem $S$, Younis $R$, Kader M. Sex determination from the piriform aperture using multi slice computed tomography: Discriminant function analysis of Egyptian population in Minia Governorate. Egypt J Forensic Sci. 2016; 6(4): 429-434, doi: 10.1016/j.ejfs.2016.11.003. 
2. Akansel G, Inan N, Kurtas O, et al. Gender and the lateral angle of the internal acoustic canal meatus as measured on computerized tomography of the temporal bone. Forensic Sci Int. 2008; 178(2-3): 93-95, doi: 10.1016/j. forsciint.2008.02.006, indexed in Pubmed: 18378102.

3. Aksu F, Mas NG, Kahveci $O$, et al. Apertura piriformis ve choana çapları: anatomik bir çalışma. Dokuz Eylül Üniveritesi Tıp Fakültesi Dergisi. 2013; 27(1): 1-6.

4. Asghar A, Dixit A, Rani M. Morphometric study of nasal bone and piriform aperture in human dry skull of indian origin. J Clin Diagn Res. 2016; 10(1): AC05-AC07, doi: 10.7860/ JCDR/2016/15677.7148, indexed in Pubmed: 26894050.

5. Citardi MJ, Hardeman S, Hollenbeak $C$, et al. Computer-aided assessment of bony nasal pyramid dimensions. Arch Otolaryngol Head Neck Surg. 2000; 126(8): 979-984, indexed in Pubmed: 10922231.

6. Hommerich $C P$, Riegel $A$. Measuring of the piriform aperture in humans with 3D-SSD-CT-reconstructions. Ann Anat. 2002; 184(5): 455-459, doi: 10.1016/S09409602(02)80078-4, indexed in Pubmed: 12392325.

7. Hwang TS, Song J, Yoon Ho, et al. Morphometry of the nasal bones and piriform apertures in Koreans. Ann Anat. 2005; 187(4): 411-414, doi: 10.1016/j.aanat.2005.04.009, indexed in Pubmed: 16163855.

8. Jeon A, Sung $\mathrm{KiH}$, Kim SD, et al. Anatomical changes in the East Asian midface skeleton with aging. Folia Morphol. 2017 [Epub ahead of print]; 76(4): 730-735, doi: 10.5603/ FM.a2017.0027, indexed in Pubmed: 28353305.

9. Karadag D, Ozdol NC, Beriat K, et al. CT evaluation of the bony nasal pyramid dimensions in Anatolian people. Dentomaxillofac Radiol. 2011; 40(3): 160-164, doi: 10.1259/ $\mathrm{dmfr} / 35578628$, indexed in Pubmed: 21346082.

10. Lee SHo, Yang TY, Han GS, et al. Analysis of the nasal bone and nasal pyramid by three-dimensional computed tomography. Eur Arch Otorhinolaryngol. 2008; 265(4): 421-424, doi: 10.1007/s00405-007-0476-9, indexed in Pubmed: 17929046.

11. López MC, Galdames IS, Matamala DZ, et al. Sexual dimorphism determination by piriform aperture morphometric analysis in brazilian human skulls. Int J Morphol. 2009; 27(2), doi: 10.4067/s0717-95022009000200007.

12. McDowell JL, L’Abbé EN, Kenyhercz MW. Nasal aperture shape evaluation between black and white South
Africans. Forensic Sci Int. 2012; 222(1-3): 397.e1-397. e6, doi: 10.1016/j.forsciint.2012.06.007, indexed in Pubmed: 22727267.

13. Moreddu E, Puymerail L, Michel J, et al. Morphometric measurements and sexual dimorphism of the piriform aperture in adults. Surg Radiol Anat. 2013; 35(10): 917-924, doi: 10.1007/s00276-013-1116-2, indexed in Pubmed: 23625070.

14. Ofodile FA. Nasal bones and pyriform apertures in blacks. Ann Plast Surg. 1994; 32(1): 21-26, doi: 10.1097/ / 00000637-199401000-00005, indexed in Pubmed: 8141532.

15. Papesch E, Papesch M. The nasal pyriform aperture and its importance. Otorhinolaryngology-Head Neck Surg. 2016; 1(4), doi: 10.15761/ohns.1000122.

16. Prado F, Caldas R, Rossi A, et al. Piriform aperture morphometry and nasal bones morphology in Brazilian population by postero-anterior caldwell radiographys. Int J Morphol. 2011; 29(2): 393-398, doi: 10.4067/s071795022011000200014.

17. Schultz A. Relation of the external nose to the bony nose and nasal cartilages in whites and negroes. Am J Phys Anthropol. 1918; 1(3): 329-338, doi: 10.1002/ ajpa.1330010304.

18. Turhan-Haktanir N, Ayçiçek A, Haktanir A, et al. Variations of supraorbital foramina in living subjects evaluated with multidetector computed tomography. Head Neck. 2008; 30(9): 1211-1215, doi: 10.1002/hed.20866, indexed in Pubmed: 18642294.

19. Uygur M, Ertürk M, Akcan A, et al. Morphometric features of the piriform aperture and nasal bones. Medeniyet Med J. 2006; 21(4): 174-177.

20. Yüzbaşioğlu N, Yilmaz $M T$, Çicekcibasi $A E$, et al. The evaluation of morphometry of nasal bone and pyriform aperture using multidetector computed tomography. J Craniofac Surg. 2014; 25(6): 2214-2219, doi: $10.1097 /$ SCS.0000000000001063, indexed in Pubmed: 25377975.

21. Zamani Naser A, Panahi Boroujeni M. CBCT evaluation of bony nasal pyramid dimensions in iranian population: a comparative study with ethnic groups. Int Sch Res Notices. 2014; 2014: 819378, doi: 10.1155/2014/819378, indexed in Pubmed: 27437462. 